\title{
Efficacy of a cell phone-based exercise programme for COPD
}

\author{
W-T. Liu*,\#, C-H. Wang*, , H-C. Lin*, , S-M. Lin*,\#, K-Y. Lee*\#, Y-L. Lo*,\#, S-H. Hung ${ }^{+}$, \\ Y-M. Chang ${ }^{+}$, K.F. Chung ${ }^{\S}$ and H-P. Kuo*,\#
}

ABSTRACT: The application of a supervised endurance exercise training programme in a home setting offering convenience and prolonged effects is a challenge.

In total, 48 patients were initially assessed by the incremental shuttle walk test (ISWT), spirometry and the Short Form-12 (SF-12) quality-of-life questionnaire, and then every 4 weeks for 3 months thereafter and again after $1 \mathrm{yr}$. During the first 3 months, 24 patients in the cell phone group were asked to perform daily endurance walking at $80 \%$ of their maximal capacity by following the tempo of music from a program installed on a cell phone. The level of endurance walking at home was readjusted monthly according to the result of ISWT. In the control group, 24 patients received the same protocol and were verbally asked to take daily walking exercise at home.

Patients in the cell phone group significantly improved their ISWT distance and duration of endurance walking after 8 weeks. The improvements in ISWT distance, inspiratory capacity and SF-12 scoring at 12 weeks persisted until the end of the study, with less acute exacerbations and hospitalisations.

In the present pilot study, the cell phone-based system provides an efficient, home endurance exercise training programme with good compliance and clinical outcomes in patients with moderate-to-severe chronic obstructive pulmonary disease.

KEYWORDS: Cell phone, chronic obstructive pulmonary disease, pulmonary rehabilitation, shuttle walking tests

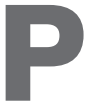

ulmonary rehabilitation is becoming an essential part of the management of patients with chronic obstructive pulmonary disease (COPD) [1, 2]. Most pulmonary rehabilitation programmes contain a comprehensive intervention that improve respiratory symptoms and exercise capacity, as well as quality of life [3]. An increasing number of reports show that pulmonary rehabilitation programmes with supervised exercise training improves exercise tolerance, quality of life, activities of daily life, respiratory symptoms, and exertional and overall dyspnoea. They also decrease the need for hospitalisation in COPD patients [4]. Most pulmonary rehabilitation programmes are hospital based and patients are expected to perform exercise sessions with regular supervision and monitoring in order to achieve persistent and optimal physiological benefits. However, compliance and the acceptance of regular visits to the hospital or clinics are major stumbling blocks to the success of these programmes [5]. Therefore, an alternative approach has been to consider home-based and self-managed rehabilitation programmes, which should also be supervised, or at least closely monitored [6-8].

Exercise training is the cornerstone of pulmonary rehabilitation and the best available means of improving muscle function and chronic respiratory symptoms in COPD patients [9, 10]. Exercise training improves skeletal muscle oxidative capacity and efficiency that leads to less alveolar ventilation for a given work rate $[11,12]$. Patients will tolerate a heavier workload with less dyspnoea on exercise [13]. The lower limbs play an important role in exercise training programmes because the quadriceps are the major muscles for patients' mobilisation [14-16]. Even with light exercise, a weak lower limb will increase ventilatory demands, thus aggravating dynamic hyperinflation in COPD patients, who may then be discouraged from undertaking further exercise $[17,18]$. A pulmonary rehabilitation programme must contain an exercise training programme that is easy to perform with good compliance and good clinical efficacy. Endurance exercise training has been reported to have consistently high clinical efficacy $[19,20]$, but how to apply a

\section{AFFILIATIONS}

${ }^{*}$ Dept of Thoracic Medicine, Chang

Gung Memorial Hospital, Taipei,

Depts of ${ }^{\#}$ Medicine, and

"Chinese Medicine, Chang Gung

University, Taoyuan, and

${ }^{+} \mathrm{IT}$ and Visualization Division

National Center for High-Performance

Computing, Hsinchu, Taiwan.

${ }^{\S}$ National Heart and Lung Institute, Imperial College London, London, UK.

CORRESPONDENCE

H-P. Kuo

Dept of Thoracic Medicine Chang Gung Memorial Hospital

199 Tun Hwa N. Rd

Taipei

Taiwan

Fax: 88633272474

E-mail: 98828@ms11.hinet.net

Received

August 102007

Accepted after revision:

May 062008

STATEMENT OF INTEREST

None declared

European Respiratory Journal Print ISSN 0903-1936 Online ISSN 1399-3003 
supervised endurance exercise training programme in the home setting for prolonged effects remains a challenge [21-24].

The current authors have developed a home-based exercise training programme for stable COPD patients. The patients were asked to walk at a speed controlled by the tempo of music from a program installed on a cell phone. The tempo of music was exactly the same as the walking speed at the intended level for endurance exercise training. The duration of endurance walking and symptom scores were recorded daily and sent by the cell phone to a website for storage and monitoring. This pilot study is the first study in COPD patients to document the clinical efficacy, compliance and applicability of a home-based exercise training programme supervised via a cell phone.

\section{MATERIALS AND METHODS}

\section{Study subjects}

In total, 48 patients with moderate-to-severe COPD were recruited into the study. The diagnosis of COPD was compliant with the criteria of the Global Initiative for Chronic Obstructive Lung Disease (GOLD) guidelines published in 2000 [25]. No subject had an acute exacerbation or received therapy with oral corticosteroids for $\geqslant 3$ months prior to the study, and all the subjects continued with a stable regimen of medications throughout the study. According to the GOLD guidelines, the diagnosis of COPD is suggested to be made in patients $>40$ yrs of age; therefore, patients aged $<40 \mathrm{y}$ yrs were excluded. In addition, patients aged $>80 \mathrm{yrs}$ were excluded, as they may experience difficulty in operating the cell phone. Subjects were also excluded if any of the following criteria applied: requirement for oxygen therapy; presence of symptomatic cardiovascular diseases or severe systemic diseases limiting exercise capacity; use of medications affecting exercise responses; musculoskeletal conditions likely to influence exercise performance; and impaired hearing or vision affecting a subject's ability to follow the exercise training programme. Initially, 60 patients were enrolled and 30 were assigned to the cell phone group according to a table of random numbers. Four patients in the cell phone group withdrew from the study within 3 weeks owing to difficulty in operating the cell phone. Another two patients in this group withdrew owing to transport problems. In the control group, two patients dropped out owing to COPD exacerbation within the first 2 weeks. Two patients in this group were lost to follow-up after 3 months and another two patients suffered from another illness affecting exercise performance and transport problems, respectively. Finally, 48 patients were recruited into the present study and 24 of them were in the cell phone group. The study was approved by the Human Research Ethics Committees of Chang Gung Memorial Hospital (Taipei, Tiawan). Informed consent was obtained from all subjects.

\section{Cell phones and software}

The software used was a Java application (Java 2 Micro Edition (J2ME)) designed by the National Center for High-Performance Computing (Hsinchu, Taiwan). It is compatible with most commercial J2ME-enabled cell phones with General Packer Radio Service (GPRS). The present study adopted the Sony Ericsson $\mathrm{K} 600 \mathrm{i}$ cell phone (Sony, Tokyo, Japan) to execute the
J2ME application for the endurance walking exercise by music pacing and data uploading through GPRS to a website.

\section{Study design}

At the start of the study, all the subjects were assessed by an incremental shuttle walking test (ISWT) [26], spirometry and the Short Form-12 (SF-12) quality-of-life questionnaire. Patients in the cell phone group were asked to take daily endurance exercise training with cell phone assistance. The level of endurance walking was reassessed and readjusted at return clinical visits every 4 weeks during the first 3 months (the exercise training period). During this period, the adherence to protocol was reinforced by telephone when patients missed 1 day of walking training. Patients were then asked to continue their exercise programme at home at a fixed walking speed and to return to the clinic every 3 months for the following 9 months (the self-management period). However, no telephone reinforcement was made during this period. The adherence and compliance of the home-based exercise training programme was assessed on the website by monitoring the frequency of performance and the duration of the endurance walking programme every week. An exacerbation of COPD was defined as a change in the patient's baseline dyspnoea, cough and/or sputum beyond normal day-to-day variations, which warranted an earlier return to the clinic for a change in regular medication, or hospitalisation [27]. Therefore, the clinical outcomes were assessed for the episodes of acute exacerbation by recording the number of unscheduled visits and hospitalisations during the period of study. Patients in the control group received the same protocol and telephone reinforcement every 2 weeks during the first 3 months of the study period. The adherence to the walking exercise at home was reported by the patients themselves at the return visits to the clinic. All the patients performed ISWT, SF-12 and spirometry measurements every month for the first 3 months and at the end of the self-management period. In both groups, each patient was provided with a home rehabilitation programme booklet and a DVD, including written instructions for home walking exercise training.

\section{Endurance walking exercise with constant intensity}

The walking speed of the endurance exercise training at home was set at $80 \%$ of the individual's maximal capacity, which could be predicted from the distance walked during the ISWT [28]. Using the following equation (1), the peak oxygen uptake $\left(V^{\prime} \mathrm{O}_{2}\right.$,peak) of ISWT could be determined. The level closest to the speed derived from $80 \%$ of the predicted $V^{\prime} \mathrm{O}_{2}$,peak value was then determined, representing $80 \%$ of the maximal capacity for endurance walking training at home [29].

$$
\begin{gathered}
\text { Predicted } V^{\prime} \mathrm{O}_{2} \text {,peak }\left(\mathrm{mL} \cdot \mathrm{min} \cdot \mathrm{kg}^{-1}\right)=4.19+ \\
(0.025 \times \mathrm{ISWT} \text { distance })
\end{gathered}
$$

During the period of ISWT, the entire test was recorded by a camcorder in order to count the number of steps per shuttle at the appropriate level. Using the walking speed and the number of steps per shuttle, the tempo of music for the appropriate walking speed was calculated using the following equation (2). The patients were then asked to follow this individualised music tempo and to walk at a fixed pace to maintain a constant speed. 


\begin{tabular}{|c|c|c|c|}
\hline & Cell phone group & Control group & $p$-value \\
\hline Subjects n & 24 & 24 & \\
\hline Age yrs & $71.4 \pm 1.7$ & $72.8 \pm 1.3$ & 0.741 \\
\hline Males & $24(100)$ & $24(100)$ & 1.000 \\
\hline Body mass index & $22.9 \pm 0.7$ & $23.5 \pm 0.7$ & 0.773 \\
\hline SF-12 PCS & $38.7 \pm 1.8$ & $40.1 \pm 1.3$ & 0.959 \\
\hline ISWT m & $255.8 \pm 20.6$ & $262.9 \pm 16.5$ & 0.464 \\
\hline FVC L & $1.87 \pm 0.07$ & $2.00 \pm 0.13$ & 0.718 \\
\hline FEV 1 L & $0.97 \pm 0.06$ & $0.99 \pm 0.06$ & 0.951 \\
\hline FEV $1 \%$ pred & $45.2 \pm 3.2$ & $46.0 \pm 2.8$ & 0.918 \\
\hline $\mathrm{FEV}_{1 / \text { FVC\% }}$ & $51.8 \pm 2.8$ & $50.8 \pm 2.4$ & 0.650 \\
\hline IC pre-ISWT L & $1.59 \pm 0.06$ & $1.69 \pm 0.12$ & 0.789 \\
\hline IC post-ISWT L & $1.30 \pm 0.06$ & $1.37 \pm 0.11$ & 0.934 \\
\hline Change in IC & $0.29 \pm 0.02$ & $0.32 \pm 0.03$ & 0.322 \\
\hline \multicolumn{4}{|c|}{$\begin{array}{l}\text { Data are presented as mean } \pm \text { SEM or } n(\%) \text {, unless otherwise stated. SF-12: } \\
\text { Short Form- } 12 \text { Health Survey; PCS: physical component summary scores; } \\
\text { ISWT: incremental shuttle walk test; FVC: forced vital capacity; FEV1: forced } \\
\text { expiratory volume in one second; \% pred: \% predicted; IC: inspiratory capacity. }\end{array}$} \\
\hline
\end{tabular}

Tempo (beats $\left.\cdot \mathrm{min}^{-1}\right)=\operatorname{speed}\left(\mathrm{km} \cdot \mathrm{h}^{-1}\right) \times 100 \times$ steps per shuttle / 60

\section{Home-based endurance exercise training}

In the cell phone group, the music software with an individualised tempo and short questionnaires for recording respiratory symptoms were installed onto the patients' cell phones after being downloaded. Patients were asked to perform endurance exercise training everyday by switching on the program on the cell phones, completing the questionnaires and walking at a speed following the tempo of the music. Patients were allowed to use earphones if the music was not loud enough for them to hear. The patients were required to keep the walking speed until they could not keep up. They then stopped walking and turned off the program. The cell phone recorded the duration of music played (equal to the duration of walking) which was then automatically sent to the website for storage by GPRS, accompanied by the data of respiratory symptom scores. On the website, the data was updated and displayed immediately.

\section{Measurements}

In the cell phone group, patients were asked to complete questionnaires on the cell phone covering respiratory symptoms, including breathlessness, cough and sputum, before they started daily endurance walking training [30]. Pulmonary function tests were performed at the beginning of the study, at the return clinical visits every 4 weeks in the first 3 months and at the end of the self-management period. The forced vital capacity (FVC), forced expiratory volume in one second (FEV1), FEV1/FVC, inspiratory capacity (IC) and breathlessness (rated by the Borg scale) were measured before and immediately after the ISWT. The walking distance of the ISWT, body mass index (BMI) and SF-12 were also recorded in both groups at each visit.

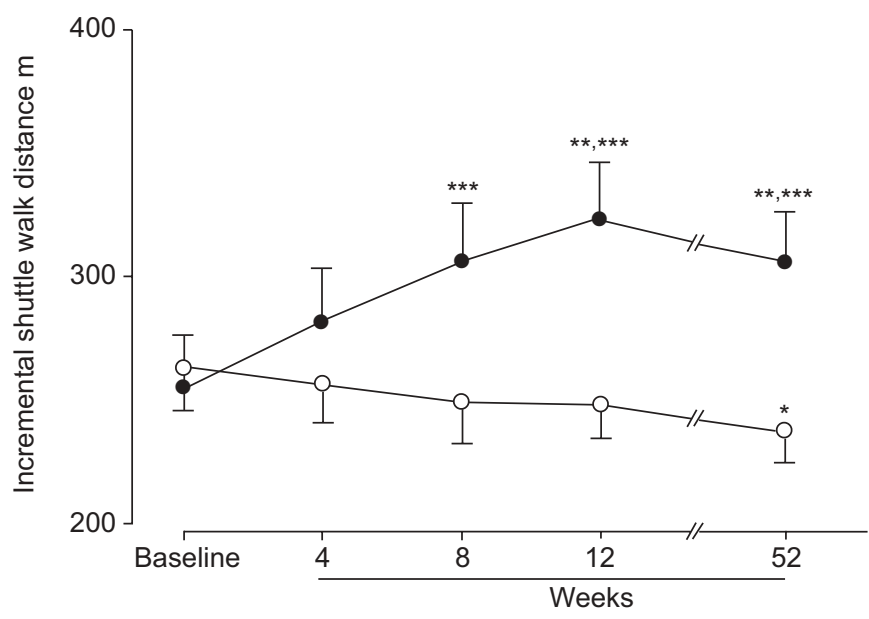

FIGURE 1. Distance covered during the incremental shuttle walk test at baseline and then every 4 weeks for 3 months and after $1 \mathrm{yr}$. In the cell phone group (-), the distance increased significantly at 8 weeks, 12 weeks and $1 \mathrm{yr}$ compared with baseline. This was greater than that of the control group ( $\bigcirc)$ after 12 weeks and $1 \mathrm{yr}$. Data presented as mean \pm SEM. *: $\mathrm{p}<0.05 ; * \star \mathrm{p}<0.01$; $* * *$ : $p<0.001$; compared with the baseline of the control group.

\section{Analysis}

The primary end-point of exercise training was change in distance in ISWT from baseline value. The sample size calculation was performed by estimating the standard deviation for increased distance in ISWT. It was calculated that 20 subjects would provide $99 \%$ statistical power for detecting a 50-m absolute difference, with a two-sided 0.05 significance level test [31, 32]. The repeated measures test of ANOVA was used to compare data within groups. The two-tailed unpaired t-test or nonparametric Mann-Whitney U-test was applied to compare results between the two groups. Statistical significance was defined as $p<0.05$. All data are presented as the mean \pm SEM.

\section{RESULTS}

\section{Patient characteristics}

The characteristics of the study subjects are shown in table 1. There were no significant differences between the two groups in terms of age, sex, BMI, initial exercise capacity, severity of COPD, pulmonary function or the extent of dynamic hyperinflation. There were no significant differences in either the maintenance medications or in the baseline SF-12 scores.

\section{Clinical efficacy of a cell phone-based endurance walking exercise programme}

\section{Exercise tolerance}

Repeated measures ANOVA revealed a significant difference in the walking distance of the ISWT in the study group $(p<0.001)$ but not in the control group $(p=0.078)$. In the cell phone group there was a statistically significant increase in the walking distance of the ISWT at 8 weeks $(307.1 \pm 23.5 \mathrm{~m}$; $\mathrm{p}<0.001)$ and at 12 weeks $(324.2 \pm 22.5 \mathrm{~m} ; \mathrm{p}<0.001)$ compared with baseline $(255.8 \pm 20.6 \mathrm{~m}$; fig. 1$)$. The improvement lasted for 9 months until the end of the self-management period $(306.7 \pm 21.2 \mathrm{~m}, \mathrm{p}<0.001$; fig. 1$)$. The distance walked in the ISWT by patients in the cell phone group was significantly 

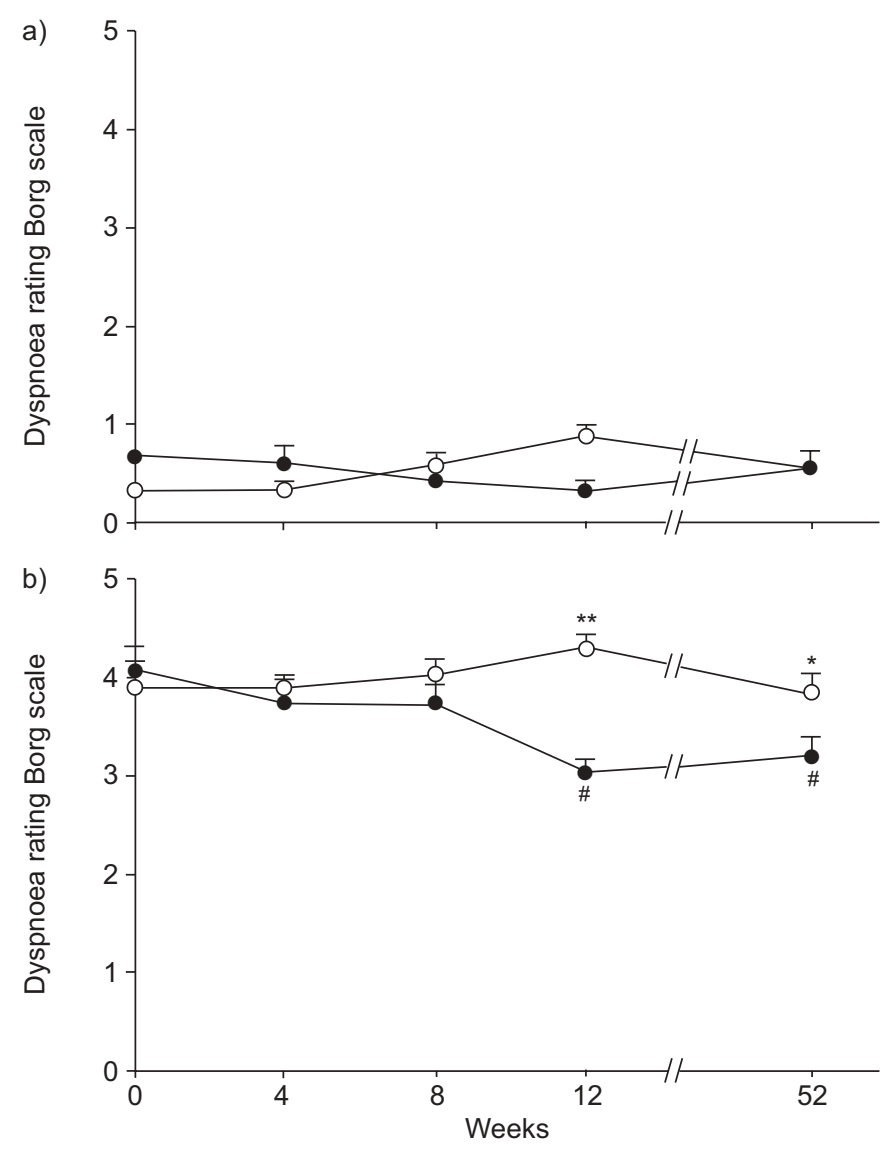

FIGURE 2. Dyspnoea rating (Borg scale) a) before and b) after incremental shuttle walk test (ISWT) at baseline and then every 4 weeks for 3 months and after $1 \mathrm{yr}$. In the control group $(\bigcirc)$, the Borg scale after ISWT was significantly greater than that of the cell phone group $(\bullet)$ at 12 weeks $(3.0 \pm 0.1$ versus $4.3 \pm 0.1, n=24)$ and after 1 yr ( $3.2 \pm 0.2$ versus $3.9 \pm 0.2)$. Data presented as mean \pm SEM. ${ }^{*}: p<0.01$ compared with the baseline of the cell phone-group. *: $p<0.05$; $* *$ : $p<0.01$ versus cell phone group.

greater than that of the control group after 12 and 52 weeks of home exercise training (fig. 1).

There was no significant change in the resting breathlessness in either group throughout the course of the study (fig. 2). However, breathlessness measured by the Borg scale after the ISWT in the cell phone group was significantly decreased compared with that of the control group after 12 weeks of endurance walking exercise at home $(3.0 \pm 0.1$ versus $4.3 \pm 0.1$; $\mathrm{p}<0.01$ ), and at the end of the self-management period ( $3.2 \pm 0.2$ versus $3.9 \pm 0.2 ; \mathrm{p}<0.05$; fig. 2 ).

\section{Endurance walking exercise at home}

Patients in the cell phone group performed the walking exercise at home at a frequency of $\sim 4-6$ days $\cdot$ week $^{-1}$ in the first 3 months. The duration of endurance walking significantly increased after 8 weeks of home exercise training $(1,887 \pm 221 \mathrm{~s})$ compared with baseline $(1,382 \pm 205 \mathrm{~s} ; \mathrm{p}<0.001)$, and a plateau was reached at 12 weeks $(2,083 \pm 230 \mathrm{~s})$. The patients' respiratory symptom scores decreased concomitantly with improvement in exercise tolerance. One patient dropped out of the control group because of acute respiratory failure requiring

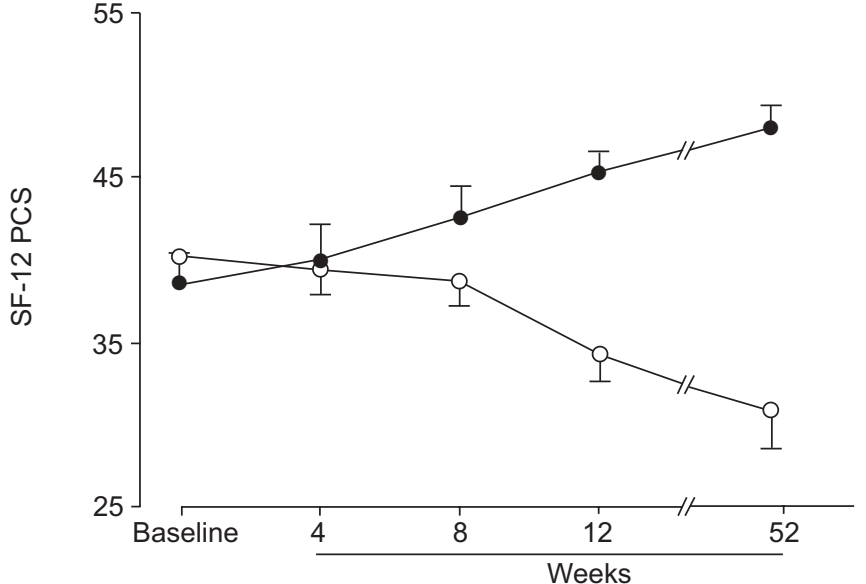

FIGURE 3. Quality of life questionnaire by Short Form-12 (SF-12) physical component summary scores (PCS) at baseline and then every 4 weeks for 3 months and after $1 \mathrm{yr}$. The SF-12 PCS values in the cell phone group (-) were significantly improved after 8 weeks $(p<0.05 ; n=24), 12$ weeks $(p<0.01 ; n=24)$ and $1 \mathrm{yr}(p<0.01 ; n=24)$ compared with the baseline, and were significantly greater than those of the control group $(\bigcirc)$ at 12 weeks $(p<0.001 ; n=24)$ and $1 \mathrm{yr}$ $(p<0.001 ; n=24)$.

intubation, leading to death in the 10th month of the study. Patients in the cell phone group were asked to keep the same pace of walking without further adjustment in the following 9 months (the self-management period) of the home-based exercise training programme. During the self-management period, all these patients persistently continued their endurance exercise programme at a similar frequency and constant workload as the program installed on the cell phone. At the end of the study, 22 (92\%) of the patients in the cell phone group maintained their regular endurance walking exercise. During the self-management period, only nine $(38 \%)$ of the patients in the control group self-reported that they had maintained the regular walking.

\section{Quality of life}

Patients in the cell phone group showed improved quality of life with significant increases in their SF-12 physical component summary (PCS) scores at 8 weeks $(42.5 \pm 1.8 ; \mathrm{p}<0.05)$ and at 12 weeks $(45.4 \pm 1.1 ; \mathrm{p}<0.01)$ compared with baseline $(38.7 \pm 1.8$; fig. 3$)$. The improvement in SF-12 PCS $(47.9 \pm 1.5$ versus $38.7 \pm 1.8 ; \mathrm{p}<0.01$ ) persisted for 9 months throughout the self-management period (fig. 3). In addition, the SF-12 PCS $(45.4 \pm 1.1$ versus $34.3 \pm 1.5 ; \mathrm{p}<0.001)$ values in the cell phone group were significantly greater than in those of the control group after 12 weeks of exercise training. This difference persisted throughout the self-management period $(47.9 \pm 1.5$ versus $30.9 \pm 2.2 ; \mathrm{p}<0.001)$. There was significant decrease of SF-12 PCS in the controls $(\mathrm{p}<0.001)$ at $1 \mathrm{yr}$ compared with the data at baseline, 4 weeks and 8 weeks $(30.9 \pm 2.2$ versus $40.1 \pm 1.3,39.5 \pm 1.7$ and $38.7 \pm 1.5$, respectively, $\mathrm{p}<0.05)$.

\section{Clinical outcomes}

The patients in both groups had GOLD stage III severity of COPD and all had previously experienced exacerbations of COPD, at the rate of one to two hospitalisations per year. Out of the 24 patients in the control group, 10 patients had 26 
TABLE 2 Clinical outcomes during the 1-yr study period

Cell phone group

Control group

\section{Subjects}

Daily regular walking

Unscheduled visit

Number of patients

Number of visits

Number of visits $\cdot$ patient $^{-1} \cdot \mathrm{yr}^{-1}$

Hospitalisation

Number of patients

Number of hospitalisations

Number of hospitalisations.

patient ${ }^{-1} \cdot \mathrm{yr}^{-1}$

Length of hospital stay

Respiratory failures

Deaths

Data are presented as $n, n(\%)$ or median (range). *: $p<0.05 ; * *: p<0.01$ compared with corresponding cell phone group.

episodes of acute exacerbation, most of which had occurred in the second half of the year, resulting in 26 unscheduled clinical visits and 22 hospitalisations in eight $(33 \%)$ of these patients. Four unscheduled visits occurred in the exercise training period and during the self-management period, four and 18 events leading to hospitalisation took place during the initial 3 months and final 6 months, respectively. There was no hospitalisation due to causes other than acute exacerbation of COPD in the control group during the study period (table 2). The median (range) length of hospital stay was 7.5 (4-20) days and the total length of hospitalisation was 191 days. In the control group, two patients suffered from acute respiratory failure requiring intubation, which lead to the death of one patient (table 2). In contrast, only two patients in the cell phone-group suffered from acute exacerbation with hospitalisation, and there were only two hospitalisations (during hospital stay of 5 and 12 days) during the 1-yr study period (table 2).

\section{Pulmonary function}

There was no significant change in FEV1 in either group. The IC in the cell phone group significantly increased after 12 weeks of endurance walking exercise at home $(1.75 \pm 0.07$ and $1.53 \pm 0.06$ L pre- and post-ISWT, respectively; $\mathrm{p}<0.001$ for both comparisons) compared with baseline (1.59 \pm 0.06 and $1.30 \pm 0.06 \mathrm{~L}$ pre- and post-ISWT, respectively; fig. $4 \mathrm{a}$ and $\mathrm{b}$ ). In the control group, there was no significant change in the IC either pre- or post-ISWT throughout the period of exercise training (fig. $4 \mathrm{a}$ and b). In addition, the change in IC on exercise, representing dynamic hyperinflation, was significantly decreased in the cell phone group $(0.21 \pm 0.03 \mathrm{~L} ; \mathrm{p}<0.001)$ when compared with the control group $(0.33 \pm 0.02 \mathrm{~L})$ after 12 weeks of endurance exercise training at home (fig. 4c). The clinical benefits of the cell phone-based exercise training programme in improving IC $(1.69 \pm 0.07 \mathrm{~L}$ pre-ISWT; $\mathrm{p}=0.004,1.48 \pm 0.06 \mathrm{~L}$ post-ISWT; $\mathrm{p}<0.001)$ and dynamic hyperinflation $(0.21 \pm 0.03 \mathrm{~L}$; $p<0.05)$ continued for 9 months until the end of the selfmanagement period (fig. 4).
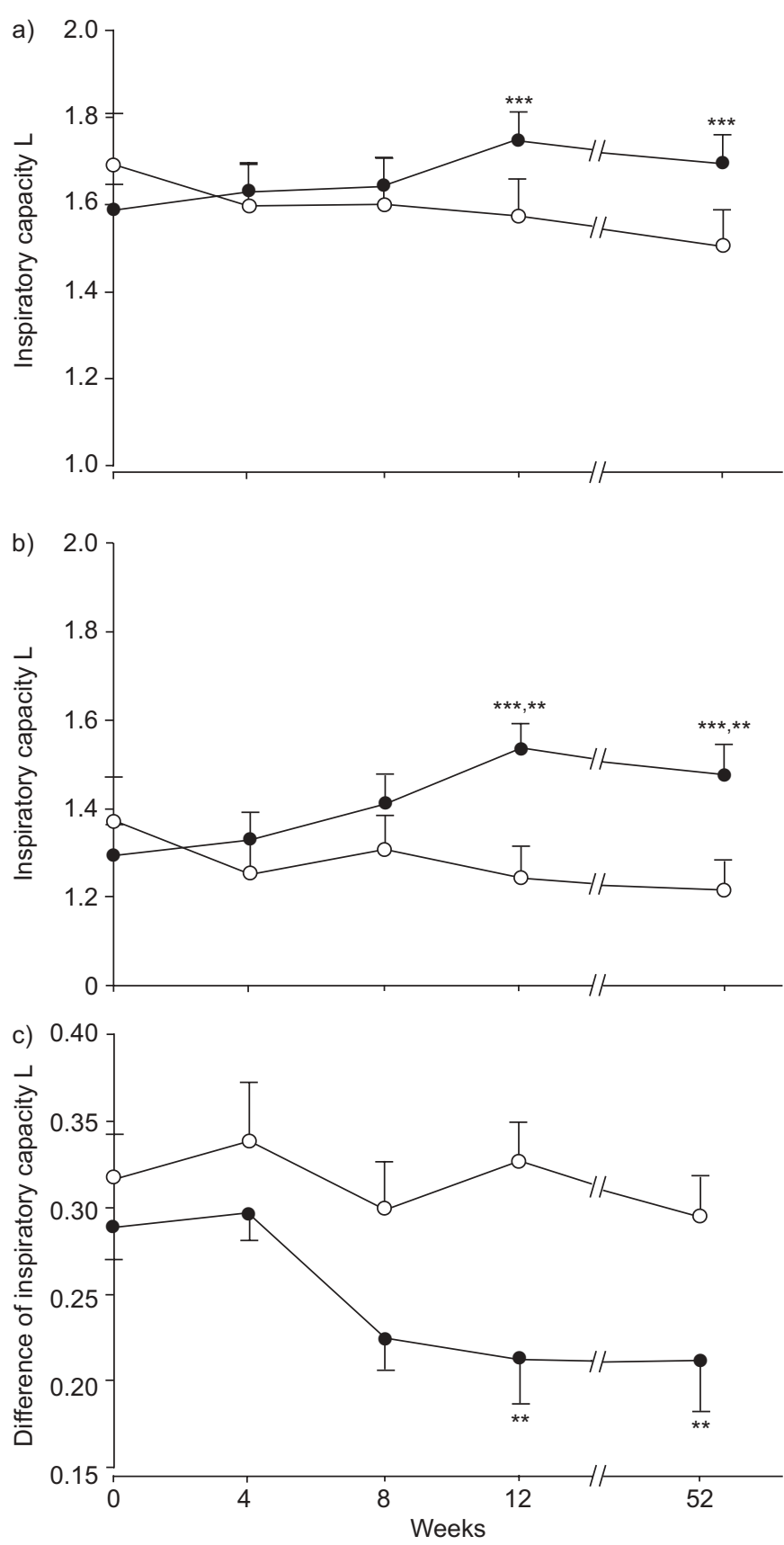

FIGURE 4. Inspiratory capacity a) before and b) after incremental shuttle walk test (ISWT) at baseline and then every 4 weeks for 3 months and after 1 yrs. a and b) In the cell phone group ( $)$, the inspiratory capacity increased after 12 weeks $(p<0.001 ; n=24)$ of endurance walking and after $1 \mathrm{yr}(p<0.001, n=24)$ both preand post-ISWT compared with baseline. c) Change in inspiratory capacity on ISWT, representing dynamic hyperinflation, was significantly decreased in the cell phone group when compared with the control group after 12 weeks $(p<0.01)$ and after $1 \mathrm{yr}(\mathrm{p}<0.01) .{ }^{* \star *}: \mathrm{p}<0.001$ compared with baseline; ${ }^{* *}: \mathrm{p}<0.01$ compared with control group.

\section{Compliance with home-based exercise}

All patients in the cell phone group were adherent to the protocol during the exercise-training period. Of these, $12(50 \%)$ patients were still adherent to the protocol throughout the selfmanagement period and undertook regular endurance exercise 
walking assisted by cell phones and sent data to the website by GPRS. In addition, 10 (42\%) patients also maintained endurance exercise with cell phone assistance, but stopped sending data by GPRS during the self-management period. Two (8\%) patients refused to continue using cell phones during the selfmanagement period. In contrast, during the self-management period, only nine $(38 \%)$ patients in the control group selfreported regular walking exercise at home (table 2).

\section{DISCUSSION}

The present study has demonstrated that COPD patients, with the assistance of cell phones, are able to perform a home-based endurance exercise training programme at an intended walking speed controlled by a preset tempo of music. The duration of the endurance walking and daily respiratory symptoms can be monitored in real-time on the website. The adherence to an exercise programme was reinforced by telephone when patients missed a day of performing their walking training during the initial 3 months of the exercisetraining period. The following 3 months of home-based exercise training, exercise capacity, respiratory symptoms, quality of life, IC before or after exercise and the change in IC on exercise, representing dynamic hyperinflation, were significantly improved in the cell phone group, but not in the control group. Without telephone reinforcement or frequent return visits to the clinic during the 9 months of the selfmanagement period, 22 (92\%) of the patients in the cell phone group were observed to maintain their regular exercise training programme at home. The clinical benefits of the endurance walking-exercise training in the cell phone-group persisted throughout the self-management period. Although the small number of patients studied precluded any definite statement about overall outcomes, it is of interest that only two patients in the cell phone group suffered from an exacerbation of COPD throughout the study, while eight patients in the control group experienced 26 episodes of acute exacerbation resulting in 22 hospitalisations and two respiratory failures.

Exercise training is the cornerstone of pulmonary rehabilitation. There are several reports showing that endurance exercise provides consistently high clinical efficacy [15, 19, 20, 33]. Training at low intensity, as well as at high intensity, achieves benefits, providing there is an equal amount of work per session [34]. However, several studies have demonstrated that patients obtain more benefit when they have a high-intensity training programme $[35,36]$. In the present study, patients in both groups received home-based endurance walking exercise training at $80 \%$ of their maximal exercise capacity. The level of their endurance exercise was adjusted in the first 3 months in order to achieve maximum physiological benefits. Thereafter, patients walked at a constant work load in the self-management period to assess the clinical outcomes, persistence of physiological benefits and compliance to the home-based exercise training programme $[37,38]$.

Most exercise training, and other pulmonary rehabilitation programmes, are executed and supervised in the hospital. These programmes usually last for 4-12 weeks. Prolonging of a supervised pulmonary rehabilitation programme for 36 months may yield larger and more endurable training effects on the functional capacity and quality of life of patients $[4,7$, 39]. However, patients should exercise at least three times per week with regular supervision in order to achieve optimal physiological benefits [40]. Owing to the necessity of regular returns to the hospital or clinics, patients' motivation and compliance are always the limiting factors [41]. Home-based rehabilitation programmes are preferred by patients, as they are able to spend more time with their families and, in addition, can adjust their training to suit their daily life. Currently, several home-based rehabilitation programmes have been developed with proven clinical benefits in quality of life and exercise tolerance [42-44]. However, some of these programmes entail an extreme degree of complexity. In many cases, in those programmes for which walking freely for a period of time is recommended, it is more difficult to establish the walking speed necessary to achieve a training effect at home [45]. A study of home-based rehabilitation has recently been conducted by HERNÁNDEZ et al. [41], using the shuttle walking test (SWT) to standardise the intensity of hometraining programmes. There was a significant improvement observed with this programme in exercise tolerance, distance walked and dyspnoea at 12 weeks of rehabilitation, but not in the pulmonary function or effort parameters (SWT or cycle ergometer) [41]. However, the frequency and duration of exercise training at home are not well controlled in most established home-based exercise training programmes.

The clinical benefits obtained by the assistance of cell phones may be attributed to several factors. First, the walking speed is exactly controlled by the tempo of music to achieve the intended level of endurance training at home. Secondly, the duration of daily endurance exercise may be a good index for overall control in the status of COPD. Using cell phones, the daily record of endurance exercise duration is well monitored. The change in endurance exercise duration may draw attention to patients themselves and physicians who observe the data on the website, and early medical intervention may be implemented to prevent deterioration of COPD control. Thirdly, the long-term adherence to exercise training is the critical factor in sustaining the clinical benefit in the home setting programme; it declines when regular monitoring is removed [46, 47]. Using internet or cell phone technology, a feasible and acceptable method for the monitoring of adherence can be provided, even in elderly COPD patients $[48,49]$. In the present study, good compliance and adherence to the exercise programme are additional factors that contribute to the maintenance of clinical benefits in the cell phone group during the self-management period.

The minimum clinically important difference of ISWT has not yet been published [50], but a review article and several new studies suggest the clinically significant difference for ISWT is 48-60 m [51]. In the present study, the difference of distance (mean $\pm \mathrm{SD}$ ) in the ISWT after exercise training at 8 weeks, 12 weeks and $1 \mathrm{yr}$ were $51.3 \pm 38.5,68.3 \pm 46.6$ and $50.8 \pm$ $49.4 \mathrm{~m}$, respectively. All of these differences had $99 \%$ power to detect these differences with a significance level $(\alpha)$ of 0.05 (two-tailed). It was suspected that the changes of distance could be larger if an endurance shuttle walk test was used rather than the ISWT [52]. However, the ISWT was performed to evaluate patients' maximal exercise capacity and determine the intensity of endurance walking at home.

The oxidative capacity and efficiency could be improved after exercise training, which leads to lower alveolar ventilation in 
the same exercise workload $[11,12]$. In the current study, the change in IC on exercise, representing dynamic hyperinflation, were significantly improved in the cell phone group. The present authors speculate that the improvement of dynamic hyperinflation may be due to less breathlessness and alveolar ventilation on exercise, allowing for more expiratory time.

There was a trend for worsening of quality of life in the control group with significant decrease of SF-12 PCS at 1 yr compared with the data at baseline, 4 weeks and 8 weeks. This could be due to the increased number of exacerbations leading to hospitalisation, most of which occurred in the second half of the year. Another possibility is due to the fact that rehabilitation exercise was undertaken only infrequently during the selfmanagement period.

Patients with COPD are heavy users of healthcare and social service resources $[53,54]$. Although the benefits of pulmonary rehabilitation in decreasing hospitalisation, emergency department visits and number of unscheduled physician visits are well known [55], most training programmes are costly in terms of time, man power and resources. In addition to this, the patient-centred outcomes of health status and training adherence should be recorded in order to ensure quality control of the rehabilitation programme [56]. The current cell phoneassisted system may provide an efficient home-based exercise training programme, due to its controlled exercise workload and web-based supervision of exercise performance and daily respiratory symptoms. Even though patients were in a homebased setting, the current authors found that patients in the cell phone group could achieve significant clinical benefits after 812 weeks of exercise training. This clinical efficacy is similar to that of most hospital-based supervised programmes [4, 10, 57]. The good adherence in the cell phone group can be attributed to the user-friendly software and accurate walking speed for patients to follow [58]. Since the software is compatible with most commercial cell phones and the data are transmitted via GPRS, the monthly cost for each patient to use such a service in Taiwan is $<$ US\$10. Some of the COPD patients may find difficulty in operating this cell phone-based system. Patients who have hearing or visual impairment or those who are not familiar with or not able to operate cell phones are not suitable for this system. It also can not be guaranteed that the patient was actually walking during the whole duration of music played. However, music-paced walking is easy to perform and the fixed speed could supervise the intensity of home-based exercise training.

In summary, the present cell phone-based system provides an efficient home endurance exercise training programme with good compliance and clinical outcomes in improving exercise capacity, breathlessness, quality of life, inspiratory capacity and air-trapping in patients with moderate-to-severe chronic obstructive pulmonary disease. It is simple, reliable, easy to perform and time and cost saving. The significant clinical benefits include a reduction in acute exacerbation and early medical intervention; this will need to be confirmed in a larger study. Good compliance may encourage establishment of a more comprehensive telemedicine model for long-term home-based rehabilitation programmes and monitoring systems.

\section{REFERENCES}

1 Nici L, Donner C, Wouters E, et al. American Thoracic Society/European Respiratory Society statement on pulmonary rehabilitation. Am J Respir Crit Care Med 2006; 173: 1390-1413.

2 Reardon J, Casaburi R, Morgan M, Nici L, Rochester C. Pulmonary rehabilitation for COPD. Respir Med 2005; 99: Suppl. B, S19-S27.

3 Takigawa N, Tada A, Soda R, et al. Comprehensive pulmonary rehabilitation according to severity of COPD. Respir Med 2007; 101: 326-332.

4 Verrill D, Barton C, Beasley W, Lippard WM. The effects of short-term and long-term pulmonary rehabilitation on functional capacity, perceived dyspnea, and quality of life. Chest 2005; 128: 673-683.

5 Maltais F, Bourbeau J, Lacasse Y, et al. A Canadian, multicentre, randomized clinical trial of home-based pulmonary rehabilitation in chronic obstructive pulmonary disease: rationale and methods. Can Respir J 2005; 12 193-198.

6 Murphy N, Bell C, Costello RW. Extending a home from hospital care programme for COPD exacerbations to include pulmonary rehabilitation. Respir Med 2005; 99: 1297-1302.

7 Cockram J, Cecins N, Jenkins S. Maintaining exercise capacity and quality of life following pulmonary rehabilitation. Respirology 2006; 11: 98-104.

8 Norweg AM, Whiteson J, Malgady R, Mola A, Rey M. The effectiveness of different combinations of pulmonary rehabilitation program components: a randomized controlled trial. Chest 2005; 128: 663-672.

9 Butcher SJ, Jones RL. The impact of exercise training intensity on change in physiological function in patients with chronic obstructive pulmonary disease. Sports Med 2006; 36: 307-325.

10 Porszasz J, Emtner M, Goto S, Somfay A, Whipp BJ, Casaburi R. Exercise training decreases ventilatory requirements and exercise-induced hyperinflation at submaximal intensities in patients with COPD. Chest 2005; 128: 2025-2034.

11 Mercken EM, Hageman GJ, Schols AM, Akkermans MA, Bast A, Wouters EF. Rehabilitation decreases exerciseinduced oxidative stress in chronic obstructive pulmonary disease. Am J Respir Crit Care Med 2005; 172: 994-1001.

12 Demirbag R, Yilmaz R, Guzel S, Celik H, Kocyigit A, Ozcan E. Effects of treadmill exercise test on oxidative/ antioxidative parameters and DNA damage. Anadolu Kardiyol Derg 2006; 6: 135-140.

13 Gigliotti F, Coli C, Bianchi R, et al. Exercise training improves exertional dyspnea in patients with COPD: evidence of the role of mechanical factors. Chest 2003; 123: 1794-1802.

14 Castagna O, Boussuges A, Vallier JM, Prefaut C, Brisswalter J. Is impairment similar between arm and leg cranking exercise in COPD patients? Respir Med 2007; 101: 547-553.

15 Allaire J, Maltais F, Doyon JF, et al. Peripheral muscle endurance and the oxidative profile of the quadriceps in patients with COPD. Thorax 2004; 59: 673-678.

16 Van't Hul A, Harlaar J, Gosselink R, Hollander $P$, Postmus P, Kwakkel G. Quadriceps muscle endurance in 
patients with chronic obstructive pulmonary disease. Muscle Nerve 2004; 29: 267-274.

17 Katsura H, Yamada K, Wakabayashi R, Kida K. The impact of dyspnoea and leg fatigue during exercise on healthrelated quality of life in patients with COPD. Respirology 2005; 10: 485-490.

18 Gigliotti F, Coli C, Bianchi R, et al. Arm exercise and hyperinflation in patients with COPD: effect of arm training. Chest 2005; 128: 1225-1232.

19 Koppers RJ, Vos PJ, Boot CR, Folgering HT. Exercise performance improves in patients with COPD due to respiratory muscle endurance training. Chest 2006; 129: 886-892.

20 Steiner MC. Endurance versus strength training in chronic obstructive pulmonary disease: 1) endurance training. Chron Respir Dis 2004; 1: 38-39.

21 Ashworth NL, Chad KE, Harrison EL, Reeder BA, Marshall SC. Home versus center based physical activity programs in older adults. Cochrane Database Systematic Rev 2005; 1: CD004017.

22 Ferrari M, Vangelista A, Vedovi E, et al. Minimally supervised home rehabilitation improves exercise capacity and health status in patients with COPD. Am J Phys Med Rehabil 2004; 83: 337-343.

23 Ries AL, Kaplan RM, Myers R, Prewitt LM. Maintenance after pulmonary rehabilitation in chronic lung disease: a randomized trial. Am J Respir Crit Care Med 2003; 167: 880888.

24 Oh EG. The effects of home-based pulmonary rehabilitation in patients with chronic lung disease. Int J Nurs Stud 2003; 40: 873-879.

25 Bartsch P. [Chronic obstructive pulmonary disease (COPD) and international guidelines]. Rev Med Liege 2000; 55: 332-336.

26 Singh SJ, Morgan MD, Scott S, Walters D, Hardman AE. Development of a shuttle walking test of disability in patients with chronic airways obstruction. Thorax 1992; 47: 1019-1024.

27 Anzueto A, Sethi S, Martinez FJ. Exacerbations of chronic obstructive pulmonary disease. Proc Am Thorac Soc 2007; 4: 554-564.

28 Punzal PA, Ries AL, Kaplan RM, Prewitt LM. Maximum intensity exercise training in patients with chronic obstructive pulmonary disease. Chest 1991; 100: 618-623.

29 Singh SJ, Morgan MD, Hardman AE, Rowe C, Bardsley PA. Comparison of oxygen uptake during a conventional treadmill test and the shuttle walking test in chronic airflow limitation. Eur Respir J 1994; 7: 2016-2020.

30 Leidy NK, Rennard SI, Schmier J, Jones MK, Goldman M. The breathlessness, cough, and sputum scale: the development of empirically based guidelines for interpretation. Chest 2003; 124: 2182-2191.

31 Turner SE, Eastwood PR, Cecins NM, Hillman DR, Jenkins SC. Physiologic responses to incremental and self-paced exercise in COPD: a comparison of three tests. Chest 2004; 126: 766-773.

32 Sewell L, Singh SJ, Williams JE, Collier R, Morgan MD. How long should outpatient pulmonary rehabilitation be? A randomised controlled trial of 4 weeks versus 7 weeks. Thorax 2006; 61: 767-771.
33 Troosters T. Endurance versus strength training in chronic obstructive pulmonary disease: 2) resistance training. Chron Respir Dis 2004; 1: 40-41.

34 Normandin EA, McCusker C, Connors M, Vale F, Gerardi D, ZuWallack RL. An evaluation of two approaches to exercise conditioning in pulmonary rehabilitation. Chest 2002; 121: 1085-1091.

35 Casaburi R, Porszasz J, Burns MR, Carithers ER, Chang RS, Cooper CB. Physiologic benefits of exercise training in rehabilitation of patients with severe chronic obstructive pulmonary disease. Am J Respir Crit Care Med 1997; 155: 1541-1551.

36 Maltais F, LeBlanc $\mathrm{P}$, Jobin J, et al. Intensity of training and physiologic adaptation in patients with chronic obstructive pulmonary disease. Am J Respir Crit Care Med 1997; 155: 555-561.

37 O'Donnell DE, Hamilton AL, Webb KA. Sensory-mechanical relationships during high-intensity, constant-work-rate exercise in COPD. J Appl Physiol 2006; 101: 1025-1035.

38 Puente-Maestu L, Garcia de Pedro J, Martinez-Abad Y, Ruiz de Ona JM, Llorente D, Cubillo JM. Dyspnea, ventilatory pattern, and changes in dynamic hyperinflation related to the intensity of constant work rate exercise in COPD. Chest 2005; 128: 651-656.

39 Rossi G, Florini F, Romagnoli M, et al. Length and clinical effectiveness of pulmonary rehabilitation in outpatients with chronic airway obstruction. Chest 2005; 127: 105-109.

40 Ringbaek TJ, Broendum E, Hemmingsen L, et al. Rehabilitation of patients with chronic obstructive pulmonary disease. Exercise twice a week is not sufficient! Respir Med 2000; 94: 150-154.

41 Hernández MT, Rubio TM, Ruiz FO, Riera HS, Gil RS, Gómez JC. Results of a home-based training program for patients with COPD. Chest 2000; 118: 106-114.

42 Wijkstra PJ, van der Mark TW, Kraan J, van Altena R, Koeter GH, Postma DS. Long-term effects of home rehabilitation on physical performance in chronic obstructive pulmonary disease. Am J Respir Crit Care Med 1996; 153: 1234-1241.

43 Strijbos JH, Postma DS, van Altena R, Gimeno F, Koeter GH. A comparison between an outpatient hospitalbased pulmonary rehabilitation program and a home-care pulmonary rehabilitation program in patients with COPD. A follow-up of 18 months. Chest 1996; 109: 366-372.

44 Strijbos JH, Postma DS, van Altena R, Gimeno F, Koeter GH. Feasibility and effects of a home-care rehabilitation program in patients with chronic obstructive pulmonary disease. J Cardiopulm Rehabil 1996; 16: 386-393.

45 Wedzicha JA, Bestall JC, Garrod R, Garnham R, Paul EA, Jones PW. Randomized controlled trial of pulmonary rehabilitation in severe chronic obstructive pulmonary disease patients, stratified with the MRC dyspnoea scale. Eur Respir J 1998; 12: 363-369.

46 O'Shea SD, Taylor NF, Paratz JD. ...But watch out for the weather: factors affecting adherence to progressive resistance exercise for persons with COPD. J Cardiopulm Rehabil Prev 2007; 27: 166-174.

47 Arnold E, Bruton A, Ellis-Hill C. Adherence to pulmonary rehabilitation: a qualitative study. Respir Med 2006; 100: 1716-1723. 
48 Nguyen HQ, Wolpin S, Chiang KC, Cuenco D, CarrieriKohlman V. Exercise and symptom monitoring with a mobile device. AMIA Annu Symp Proc 2006; 1047.

49 Dale J, Connor S, Tolley K. An evaluation of the west Surrey telemedicine monitoring project. J Telemed Telecare 2003; 9: Suppl. 1, S39-S41.

50 Palange $\mathrm{P}$, Ward SA, Carlsen $\mathrm{KH}$, et al. Recommendations on the use of exercise testing in clinical practice. Eur Respir J 2007; 29: 185-209.

51 Singh SJ, Morgan MD. How long should a course of rehabilitation be? Chron Respir Dis 2007; 4: 3-4.

52 Eaton T, Young P, Nicol K, Kolbe J. The endurance shuttle walking test: a responsive measure in pulmonary rehabilitation for COPD patients. Chron Respir Dis 2006; 3: 3-9.

53 Mapel DW, McMillan GP, Frost FJ, et al. Predicting the costs of managing patients with chronic obstructive pulmonary disease. Respir Med 2005; 99: 1325-1333.
54 Tynan AJ, Lane SJ. COPD: illness severity, resource utilisation and cost. Ir Med J 2005; 98, 41-42: 44-45.

55 Golmohammadi K, Jacobs P, Sin DD. Economic evaluation of a community-based pulmonary rehabilitation program for chronic obstructive pulmonary disease. Lung 2004; 182: 187-196.

56 Californian Pulmonary Rehabilitation Collaborative Group. Effects of pulmonary rehabilitation on dyspnea, quality of life, and healthcare costs in California. J Cardiopulm Rehabil 2004; 24: 52-62.

57 Vogiatzis I, Williamson AF, Miles J, Taylor IK. Physiological response to moderate exercise workloads in a pulmonary rehabilitation program in patients with varying degrees of airflow obstruction. Chest 1999; 116: 1200-1207.

58 Arnold R, Ranchor AV, Koeter GH, et al. Changes in personal control as a predictor of quality of life after pulmonary rehabilitation. Patient Educ Couns 2006; 61: 99-108. 